\title{
Diagnóstico clínico, laboratorial e tratamento cirúrgico do carcinoma de células escamosas no genital de equinos machos: relatos de dois casos*
}

\section{Clinical and laboratorial diagnosis and surgical treatment of genital squamous cell carcinoma in male horses: report of two cases}

Andressa Sabine Rabbers, ${ }^{* *}$ Rogério Elias Rabelo, ${ }^{* * *}$ Valcinir Aloísio Scalla Vulcani, ${ }^{* * *}$ Fabiano José Ferreira de Sant'ana, ${ }^{* * * *}$ Caroline Rocha de Oliveira Lima, ${ }^{* * * * * *}$ Luiz Antônio Franco da Silva ${ }^{* * * * * *}$

\begin{abstract}
Resumo
O carcinoma de células escamosas (CCE) tem importância relevante na rotina clínica e cirúrgica de equinos e o diagnóstico dessa neoplasia é baseado nos exames clínico e histopatológico. Como a terapia conservativa raramente apresenta resultados satisfatórios, a intervenção cirúrgica tem-se mostrado mais vantajosa, constituindo, em algumas situações, como única alternativa para evitar o comprometimento morfofuncional da estrutura anatômica ou mesmo o óbito do paciente. Este estudo objetivou estabelecer o diagnóstico clínico e laboratorial de CCE genital em equinos, descrever o tratamento cirúrgico empregando sutura captonada como alteração da técnica convencional e avaliar os procedimentos pós-operatórios. Foram utilizados dois animais do sexo masculino, com cerca de 20 anos, um mestiço Apaloosa e outro pônei. Após o diagnóstico clínico foram submetidos ao tratamento cirúrgico mediante anestesia geral e colheita de material para exames citológico e histopatológico. O resultado do exame histopatológico confirmou a suspeita diagnóstica de CCE. Concluiu-se que os exames clínicos e histopatológicos são fundamentais para se estabelecer o diagnóstico do CCE genital em equinos do sexo masculino, porém, para evitar dois procedimentos anestésicos subsequentes e minimizar possíveis complicações decorrentes da anestesia, a colheita de material para avaliação laboratorial deve ser realizada durante o tratamento cirúrgico.
\end{abstract}

Palavras-chave: cirurgia, pênis, neoplasia.

\begin{abstract}
Squamous cell carcinoma (SCC) has relevant importance in the clinical and surgery of equines and the diagnosis is based on clinical and histopathological exams. The conservative therapy rarely gives satisfactory results while the surgical intervention is more advantageous, constituting, in some situations, the only alternative to avoid compromising anatomical structure or even the death of the patient. This study aimed to establish the clinical and laboratory diagnosis of genital SCC, describing the quilled suture as changing the conventional technique and evaluating postoperative procedures. Were used two male animals, about 20 years old, a half-breed appaloosa and other pony. After the clinical diagnosis, underwent surgery under general anesthesia and collection of material for histopathological examination. The results of this examination confirmed the suspected diagnosis. It was concluded that the clinical and histopathological tests are essential to establish the diagnosis of genital SCC in male horses, however. To avoid two subsequent anesthesia and minimize possible complications during the proceeding, material for laboratory evaluation should be collected during surgery.
\end{abstract}

Keywords: cancer, penile, surgery.

\section{Introdução}

Dentre as neoplasias cutâneas, o carcinoma de células escamosas (CCE) acomete, principalmente, a genitália externa de equinos (Van Den Top et al., 2011). Estudos indicam que os animais orquiectomizados são mais predispostos a essa neoplasia do que os garanhões, possivelmente devido à menor exposição da parte livre do pênis, resultando em maior acúmulo de esmegma (Edwards, 2008). Van Den Top et al.
(2010) referem-se ao esmegma como um fator de risco na etiopatogenia do CCE. Já Meuten (2002), Valentine et al. (2005) e Rabelo et al. (2013), apontaram que a exposição prolongada à luz ultravioleta, ausência de pigmento epidermal, presença de áreas alopécicas ou com reduzida cobertura de pelos são considerados fatores de risco mais importantes. Badial et al. (2010) e Bogaert et al. (2012) acrescentaram que feridas crônicas e os papilomas genitais são lesões primárias que podem dar origem ao CCE.

\footnotetext{
"Recebido em 23 de outubro de 2013 e aceito em 7 de fevereiro de 2014.

**Aluna do Programa de Residência Médico-Veterinária, Universidade Federal de Goiás, Jataí, GO, Brasil. andressarabbers@hotmail.com.

***Professor Adjunto, Setor de Cirurgia de Grandes Animais, Curso de Medicina Veterinária, Universidade Federal de Goiás, Jataí, GO, Brasil.

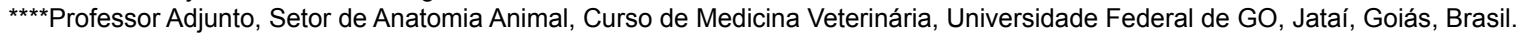

*****Professor Adjunto, Setor de Patologia Animal, Curso de Medicina Veterinária, Universidade de Brasília, Brasília, DF, Brasil.

******Doutora em Ciência Animal. Fiscal da Agrodefesa, Jataí, GO, Brasil.

*******Professor Associado IV, Setor de Clínica e Cirurgia da EVZ- Universidade Federal de Goiás, Goiânia, GO, Brasil.
} 
A anamnese, histórico, avaliação clínica do paciente e da lesão são fundamentais no diagnóstico do CCE. Porém, a confirmação só é possível pelos exames complementares com destaque para o citológico e histopatológico (McGavin e Zachary, 2009). O diagnóstico diferencial deve ser realizado com o sarcoide, pitiose, habronemose, tecido de granulação exuberante, estefanofilariose, papiloma e com o fibropapiloma, sendo a exclusão só possível por meio de exames laboratoriais (McGavin e Zachary, 2009; Coelho et al., 2012). A terapia fotodinâmica, quimioterapia ou crioterapia são alternativas de tratamento, mas a recuperação depende do estágio e localização da neoplasia (Reed e Bayly, 2000; Meuten, 2002). Contudo, a localização da neoformação em locais de difícil acesso é uma das barreiras neoformação localizada na região da glande peniana do cavalo mestiço era irregular, apresentava ulcerações e secreção serossanguinolenta e media cerca de 20 centímetros de diâmetro. Essas características, associadas à estenose parcial do óstio, impedia o retorno peniano à cavidade prepucial, caracterizando um quadro de parafimose e dificultava a micção (Figura 1B). Para avaliar a lesão localizada na porção livre do pênis do pônei foi necessário fazer a exposição peniana mediante administração de cloridrato de acepromazina a $1 \%$ na dose de $0,1 \mathrm{mg} / \mathrm{kg}$ por via intravenosa (IV). Na sequência, foi evidenciado o tecido neoformado que se apresentava ulcerado, com elevações irregulares e com seis centímetros de diâmetro (Figura 1D).

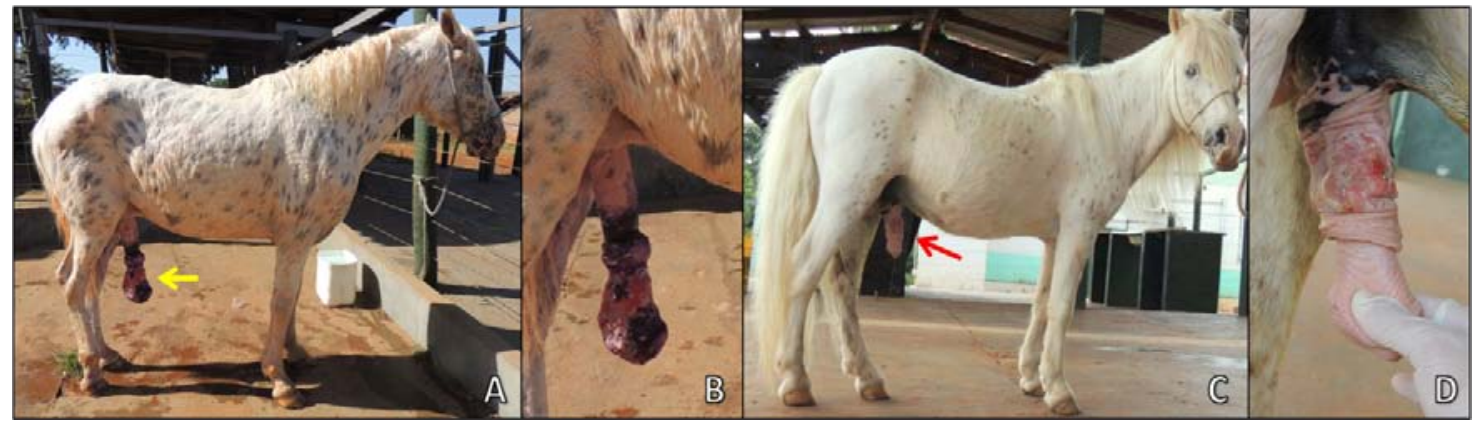

Figura 1: Neoformações na genitália externa de equinos. Em (A), cavalo orquiectomizado; a seta indica o aumento de volume na glande do pênis. Em (B), notar áreas ulceradas, disformes e com necrose. Em (C), Pônei garanhão; a seta indica a lesão na parte interna do prepúcio. Em (D), notar que a lesão situa-se em seguimento despigmentado do tecido fibroso do pênis

encontradas no emprego desses métodos conservativos (Van Den Top et al., 2011; Coelho et al., 2012).

Nessas circunstâncias, o tratamento cirúrgico tem-se apresentado como a alternativa mais viável, principalmente quando se refere às lesões extensas (Eurides e Silva, 2002). A intervenção deve ser realizada de forma ampla, com o intuito de remover toda a massa tumoral e tecido adjacente (Scott e Miller, 2010). A postectomia parcial, a falectomia e a ressecção em bloco com retroflexão peniana são as técnicas cirúrgicas mais indicadas quando o CCE localizar-se na genitália externa (Reed e Bayly, 2000; Coelho et al., 2012).

Esse estudo objetivou estabelecer o diagnóstico clínico e laboratorial do CCE genital, descrever o tratamento cirúrgico e avaliar o pós-operatório em dois equinos do sexo masculino.

\section{Relato de caso}

Dois equinos foram encaminhados ao Setor de Grandes Animais da Universidade Federal de Goiás/Regional Jataí. O primeiro (caso 1) era mestiço (Appaloosa X Mangalarga Paulista) com 18 anos de idade e castrado (Figuras $1 \mathrm{~A}$ ). O segundo (caso 2) tratava-se de um pônei com 21 anos de idade, não castrado (Figura 1C). Ambos os animais apresentavam pelagem branca, lábios, narinas e prepúcio, além do tecido fibroso do pênis despigmentados. As neoformações localizadas na genitália externa apresentavam evolução superior a oito meses.

Ao exame clínico, a frequência cardíaca, respiratória, tempo de preenchimento capilar, motilidade gastrointestinal e temperatura encontravam-se dentro dos padrões de normalidade. A
Após avaliação criteriosa dos dois casos optou-se pelo tratamento cirúrgico seguido da colheita de material para exame histopatológico, evitando-se submeter os animais a dois procedimentos anestésicos, sendo um para colher material para análise laboratorial e o outro para remoção do tecido neoformado. Especialmente no caso 1, em virtude da estenose do óstio uretral, havia risco iminente de uremia.

O pré-operatório constou de jejum completo por 12 horas, aplicação de $10 \mu \mathrm{g} / \mathrm{kg}$ de cloridrato de detomidina IV e, após 10 minutos, administração de $2 \mathrm{mg} / \mathrm{kg}$ de cloridrato de quetamina a $10 \%$ e $0,05 \mathrm{mg} / \mathrm{kg}$ do fenotiazínico diazepan, também por via IV. A manutenção da anestesia foi realizada por infusão contínua de $100 \mathrm{mg} / \mathrm{kg} / \mathrm{h}$ de éter glicerol guaiacólico (EGG) a $5 \%$ associado a $10 \mathrm{mg}$ de cloridrato de detomidina a e $1 \mathrm{~g}$ de cloridrato de quetamina. Paralelamente, utilizou-se cloridrato de acepromazina a $1 \%$, na dose de $0,1 \mathrm{mg} / \mathrm{Kg}$, IV, para induzir o relaxamento peniano e facilitar a exteriorização da parte livre do pênis. Os animais foram contidos em decúbito lateral esquerdo e o campo operatório preparado seguindo os preceitos da técnica operatória. Sequencialmente promoveu-se a anestesia infiltrativa utilizando cloridrato de lidocaína $2 \%$ sem vasoconstritor, circundando o local da incisão.

No caso 1, em virtude da gravidade da lesão, optou-se pela falectomia parcial seguindo metodologia similar à preconizada por Silva et al. (1991) e Eurides e Silva (2002). Apesar da estenose parcial do óstio uretral, foi introduzida uma sonda na uretra para orientar o cirurgião durante a etapa transcirúrgica, minimizar a contaminação do campo operatório por urina e evitar lesões iatrogênicas em estruturas adjacentes. $\mathrm{Na}$ 
sequência posicionou-se um torniquete na base do pênis para prevenção da hemorragia. Após essa etapa, promoveu-se a circuncisão da parte interna do prepúcio e, em seguida, realizouse uma incisão na face ventral do pênis envolvendo o tecido fibroso do pênis e o corpo esponjoso, de formato triangular, medindo aproximadamente três centímetros na base e quatro centímetros no comprimento. $\mathrm{O}$ ápice do triângulo foi projetado necessariamente para a porção caudal do pênis, a fim de evitar uma possível estenose uretral. Um seguimento de três centímetros de uretra foi isolado para, em seguida, realizar a abertura longitudinal por meio de uma incisão praticada em toda sua extensão.

Após amputação da extremidade do pênis comprometida e realizar a hemostasia dos principais vasos sanguíneos que foram seccionados, com a sonda uretral ainda posicionada, o corpo cavernoso foi suturado ao corpo cavernoso do pênis empregando-se fio de poliamida $\mathrm{n}^{\circ} 0$ em sutura padrão separado simples. Finalizando o procedimento, as bordas da uretra e do coto peniano remanescente foram suturados ao tecido fibroso do pênis empregando o mesmo fio e padrão de sutura. Nesta última etapa, as suturas simples foram intercaladas com captonadas visando diminuir a isquemia local e o retardo do processo cicatricial. Ao final do ato cirúrgico, removeu-se o torniquete e avaliou-se a presença de hemorragia (Figura 2, A, B, C e D).
No caso 2, para a remoção da lesão localizada no segmento anterior da parte interna e externa do prepúcio, empregouse a técnica de postectomia parcial ou também denominada circuncisão craniocaudal com encurtamento do pênis, baseandose na descrição de Silva et al. (1995) e Eurides e Silva (2002). Embora a orquiectomia fosse a conduta mais indicada, diminuindo as chances de ereção, deiscência da ferida e retardo na reparação tecidual, o proprietário não autorizou o procedimento, alegando possuir interesse na colheita de sêmen do animal, em caso de recuperação. A técnica cirúrgica constou da delimitação da área tecidual a ser removida cirurgicamente empregando quatro pinças de Kocher aplicadas na parte interna do prepúcio, sendo uma dorsal, uma ventral e duas laterais. As pinças foram fixadas equidistantes e a aproximadamente três centímetros do fundo do saco prepucial. O mesmo procedimento foi realizado com quatro pinças de Allis no tecido fibroso do pênis, caudal a porção livre do corpo do pênis e a cinco centímetros da glande.

Sequencialmente efetuou-se incisão em sentido transversal, de pinça a pinça, nos segmentos cranial e caudal da parte interna do prepúcio, próximo à extremidade livre do pênis. A seguir, promoveu-se a incisão no sentido longitudinal que se uniu às incisões transversais, previamente realizadas. $O$ tecido localizado entre as duas incisões, contendo a lesão, foi removido empregando manobras manuais e instrumentais. No

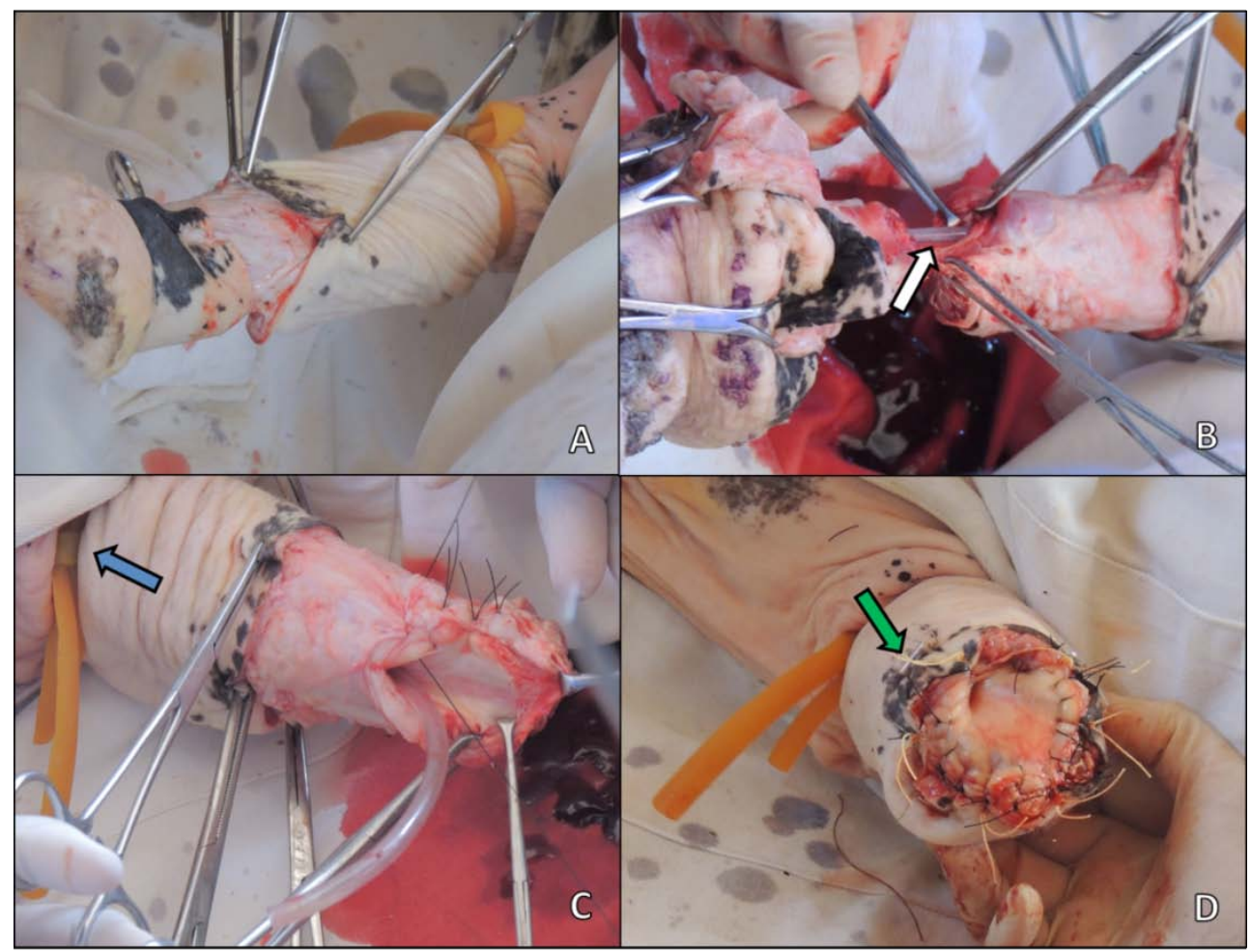

Figura 2: Falectomia parcial realizada em equino portador de neoformação. Em (A), circuncisão do tecido fibroso do pênis, realizada após sondagem uretral. Em (B), amputação da extremidade do pênis comprometida. A seta branca evidencia a presença da sonda uretral. Em (C), fixação uretral no corpo peniano por meio de sutura em padrão separado simples; note o garroteamento da base peniana, com dispositivo de látex, visando à realização da hemostasia preventiva (seta azul). Em (D), aspecto do coto peniano e da uretrostomia ao final do procedimento. A seta verde indica os cáptons 
referido caso, diferentemente da técnica convencional, as bordas da ferida apresentaram compatíveis, não sendo necessária a realização de incisões longitudinais no tecido fibroso do pênis visando promover melhor coaptação das bordas da ferida cirúrgica. Finalizando, os segmentos caudal e cranial foram aproximados, sendo aplicados pontos separados simples com fio tipo categute 3-0 para diminuir o espaço morto na ferida. Posteriormente, suturou-se as bordas em padrão Wolff captonado, empregando fio de poliamida $n^{\circ} 0$ (Figura 3 ).
Em seguida realizava-se a higienização com água e sabão neutro, seguido de solução de Dakin. A terapia local foi efetuada duas vezes ao dia, durante 25 dias consecutivos. Para se realizar a avaliação da ferida, higienização e curativos efetuava-se, diariamente, a exposição da parte livre do pênis administrando por via intravenosa, cloridrato de acepromazina a $1 \%$ na dose de $0,1 \mathrm{mg} / \mathrm{kg}$. A terapia sistêmica constou de antibioticoterapia à base de penicilina benzatina na dose de $20.000 \mathrm{Ul} / \mathrm{kg}$, de 48/48h, IM, perfazendo quatro aplicações. Para o controle do processo

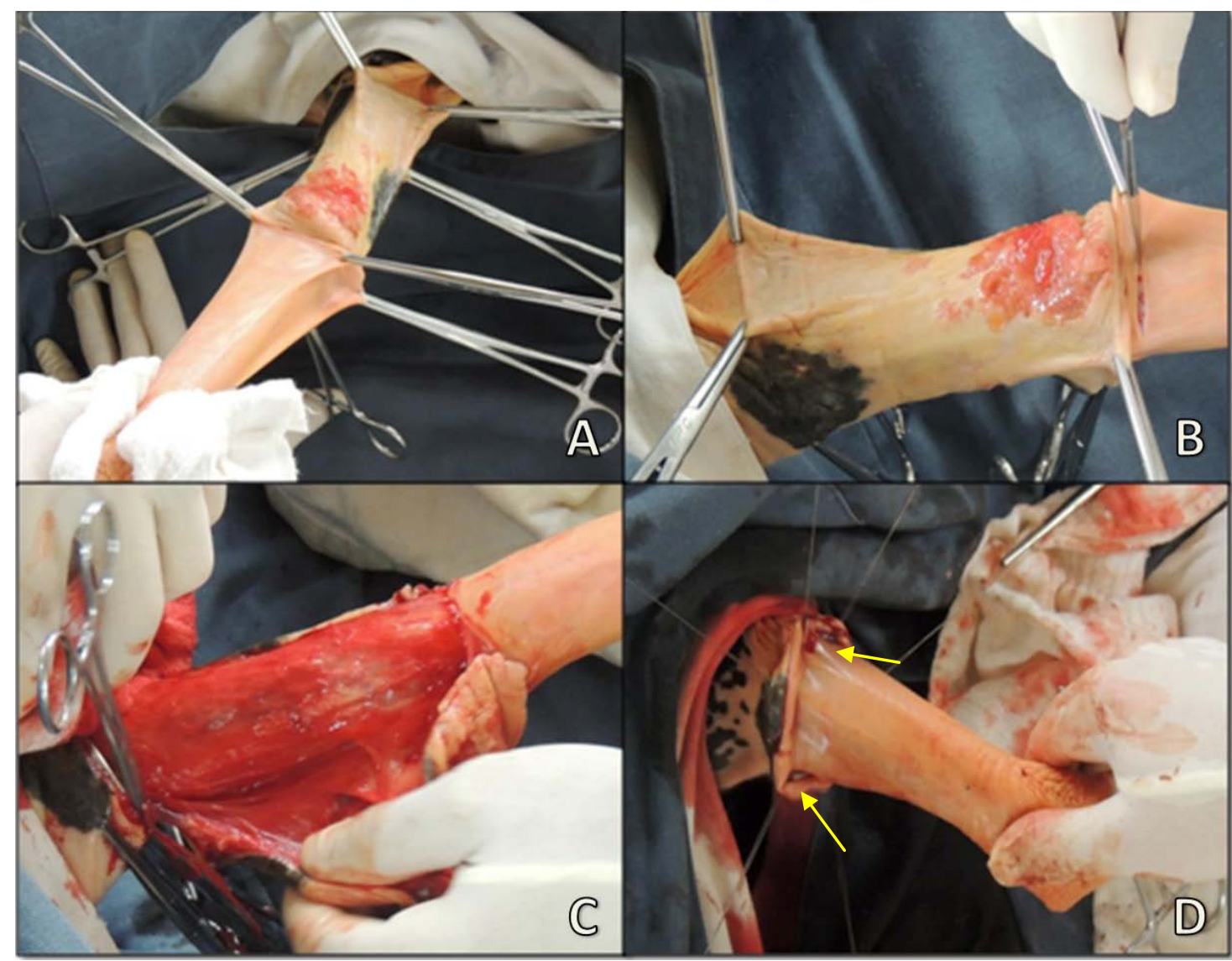

Figura 3: Circuncisão craniocaudal com encurtamento do pênis em equino portador de CCE. Em (A), delimitação craniocaudal da área tecidual a ser removida cirurgicamente. Em (B), incisão sentido transversal, de pinça a pinça, margeando os segmentos cranial e caudal da parte interna do prepúcio. $\mathrm{Em}(\mathrm{C})$, dissecação tecidual da parte interna do prepúcio, empregando manobras manuais e instrumentais, para remoção da área de neoplasia. Em (D), sutura das bordas da ferida cirúrgica, em padrão Wolff captonado, com fio de poliamida. Notar o emprego de cáptons (setas amarelas)

Em ambos os casos, por ocasião da intervenção cirúrgica, foi realizada a colheita de fragmentos do tecido neoformado para o exame histopatológico. O material foi conservado em frascos contendo formol $10 \%$. Na sequência, foi realizada punção aspirativa empregando-se agulha fina (PAAF) dos linfonodos inguinais para verificar possível metástase, visto que essas estruturas anatômicas apresentam função sentinela para essa enfermidade. O aspirado foi depositado em uma lâmina de vidro, previamente limpa e identificada, e fixado em álcool $95 \%$, sendo enviados ao Laboratório de Patologia Animal (LPV) da UFG/Regional Jataí.

O pós-operatório de ambos os casos consistiu no uso de ducha com água sob pressão na ferida cirúrgica durante dez minutos. inflamatório e analgesia utilizou-se cetoprofeno na dosagem de $2 \mathrm{mg} / \mathrm{kg}$, IV, diariamente por quatro aplicações. Os pontos foram removidos aos 14 dias do ato cirúrgico.

As intercorrências pós-operatórias foram mínimas. Excepcionalmente no caso 1 , verificou-se um discreto foco de necrose tecidual aos 13 dias, sendo atribuído à isquemia promovida pelo fio de sutura. A remoção dos pontos permitiu resolução da complicação, sendo observada reparação clínica organizada, sem tecido de granulação exacerbado nos dias seguintes. Aos 45 dias o animal recebeu alta, sem sinais de estenose uretral e ausência de disúria. No caso 2 , foi verificado edema moderado nas primeiras 48 horas, contornado pela realização 
dos procedimentos pós-operatórios. O animal recebeu alta aos 30 dias, estando a ferida reparada clinicamente. Recomendouse ao proprietário manter o animal separado de fêmeas por um período mínimo de 60 dias.

A avaliação histopatológica confirmou a suspeita clínica de CCE em ambos os casos. Observou-se pleomorfismo celular e nuclear moderado e formação de pérolas de queratina, achado patognomônico dessa neoplasia. Verificou-se também, proliferação expansiva, invasiva e irregular do epitélio para a derme, formando múltiplos agregados celulares e projeções digitiformes de queratinócitos neoplásicos (Figura 4). Os exames citológicos, referentes ao aspirado de linfonodos, apresentaram resultados negativos para presença de células neoplásicas, não confirmando, dessa forma, a ocorrência de metástases. era um equino castrado, situação que confere apenas ereção eventual e menor exposição da parte livre do pênis, sabe-se que nesses casos o acúmulo de esmegma no interior da cavidade prepucial é inevitável. De acordo com Meuten (2002), o esmega prepucial apresenta potencial carcinogênico e, portanto, pode ter sido um dos fatores que contribuíram para o início da doença no animal relatado no caso 1.

Ao contrário do caso 1, o menor acúmulo de esmegma verificado no caso 2 não foi suficiente para impedir a ocorrência do CCE. Portanto, analisando isoladamente a despigmentação da genitália externa, é possível que esse foi o fator de risco mais importante para o surgimento do processo neoplásico. Porém, como os garanhões, especialmente, os pôneis apresentem libido acentuada e se masturbam com frequência, não se pode

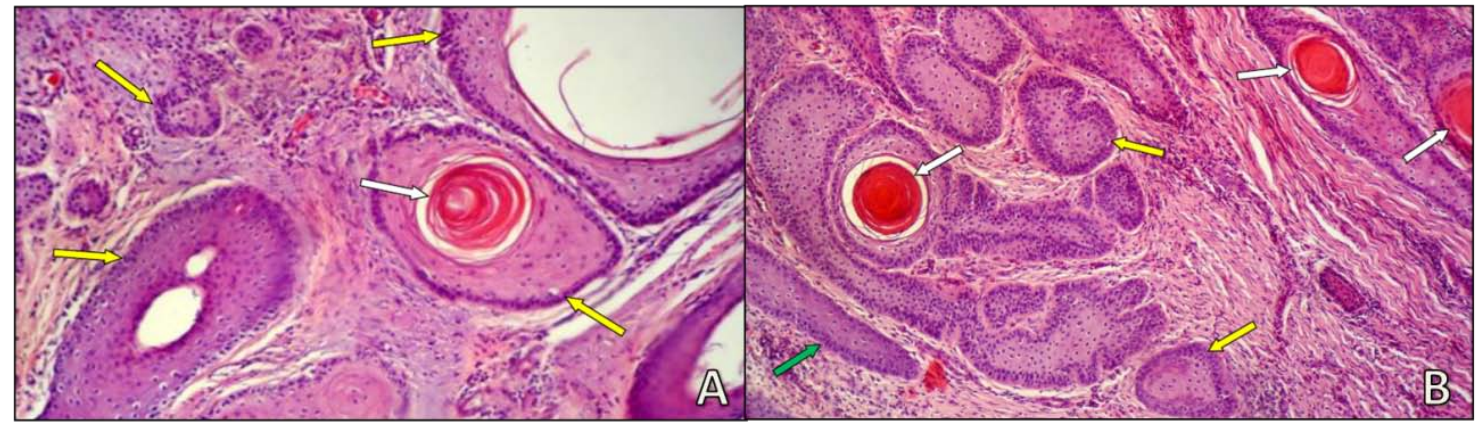

Figura 4: Fotomicrografia do CCE dos equinos submetidos à intervenção cirúrgica. As imagens (A) e (B), correspondem, respectivamente aos exames histopatológicos dos casos 1 e 2. As imagens evidenciam a presença de pérolas de queratina (setas brancas), de células epiteliais na derme (setas amarelas) e de formação de processos digitiformes (seta verde)

\section{Discussão}

O CCE nos animais aqui relatados reflete uma situação comum entre animais domésticos. Particularmente, nos equinos, essa neoplasia tem se destacado entre as alterações que requerem tratamento clínico e cirúrgico e, dependendo da localização, estágio, idade e da atividade que o animal desempenha, pode acarretar prejuízos consideráveis aos criatórios. Autores como Van Den Top et al. (2010) e Coelho et al. (2012) usaram argumentação semelhante para ressaltar a importância do assunto.

Ponderando sobre os fatores de risco relacionados ao desenvolvimento de CCE e considerando os casos descritos no presente estudo, não se pode negligenciar o fato de aspectos multifatoriais como a idade, pigmentação da pele e tecido fibroso do pênis apresentar alguma relação com a manifestação da enfermidade. Essa argumentação, em parte, esta de acordo com Thomassian (2005), que relacionou a senilidade à ocorrência de neoplasias, em especial o CCE. Ao contrário do que ocorrem em animais com pele despigmentada, segundo Reed e Bayly (2000) e Ginn et al. (2007), a pigmentação conferida à pele pela melanina tem sua produção aumentada durante a radiação ultravioleta. O pigmento é depositado sobre a superfície do núcleo celular, atuando como um envoltório protetor do DNA celular. Nessas circunstâncias reduz o risco de lesões ao material genético e o consequente desenvolvimento de neoplasias.

Ainda ponderando sobre a etiopatogenia do CCE, algumas particularidades relacionadas ao indivíduo devem ser consideradas. Como um dos casos relatados no presente estudo desconsiderar que essa circunstância favorece a ocorrência de lesões na genitália (Cattelan et al., 2004; Coelho et al., 2012). Assim sendo, lesões repetidas no tecido fibroso do pênis e na parte interna do prepúcio, associado à despigmentação podem ter intensificado a ação carcinogênica dos dois fatores, facilitado o desenvolvimento do CCE. Autores como Thomassian (2005), Badial et al. (2010) e Bogaert (2012) relacionaram as injúrias traumáticas e ausência de pigmentação ao desencadeamento do CCE, portanto, está de acordo com a possível gênese da neoplasia descrita nesse caso.

Apesar da suspeita clínica de CCE ter sido proposta em ambos os casos, o diagnóstico definitivo somente foi obtido após confirmação histopatológica. De acordo com McGavin e Zachary (2009), somente com a associação de técnicas laboratoriais, o profissional pode confirmar o diagnóstico. Quanto à punção aspirativa, embora o exame tenha apresentado resultado negativo, não se pode desconsiderar sua importância, pois esta análise auxilia na determinação da gravidade do quadro clínico, possível ocorrência de metástases, fornecendo assim, informações para o estabelecimento do prognóstico de cada caso. Micali et al. (2006) e Van Den Top et al. (2008) também ressaltaram a importância na investigação dos linfonodos inguinais em casos de neoplasias acometendo a genitália de equinos descrevendo que a presença de linfonodos reativos pode ser um indicativo de metástases. Porém os mesmos autores salientaram que diagnósticos falsos positivos podem ocorrer em virtude de infecções secundárias concomitantes, levando a quadro de linfadenite. Assim, exames citopatológicos são essenciais, dando respaldo à conduta adotada neste relato. 
Mesmo sendo um procedimento usual efetuar primeiramente a confirmação diagnóstica de CCE para em seguida instituir o protocolo terapêutico mais apropriado, nos casos descritos nesse estudo, optou-se inicialmente pela exérese tumoral seguida da colheita de material para exame histopatológico. Em decorrência da severidade dos casos, idade dos animais, extensão e cronicidade dos processos, adotando essa conduta, não foi necessário realizar a biópsia e em outra etapa efetuar a remoção da massa neoplásica. Sendo assim, a exposição dos equinos a apenas um procedimento anestésico, visou, sobretudo, preservar a integridade física dos animais cuja senilidade representava um fator de risco eminente, corroborando com as recomendações de Massone (2003).

Os procedimentos cirúrgicos de falectomia parcial (Silva et al., 1991, Eurides e Silva, 2002) e circuncisão craniocaudal com encurtamento do pênis (Silva et al., 1995, Silva et al., 2010), referentes aos casos 1 e 2, são comprovadamente eficientes, entretanto pode-se apontar que as modificações adotadas neste estudo, empregando a sutura captonada, minimizou as intercorrências pós-operatórias, como a isquemia e a deiscência, contribuindo pra uma recuperação mais rápida dos pacientes. As complicações citadas são comuns nas técnicas convencionais acima descritas, sendo atribuídas, em parte, à tensão e trauma promovido pelos fios de sutura empregados para fixar as bordas da uretra ao tecido fibroso do pênis. Apesar de não ter sido encontrado, na literatura consultada, dados acerca da utilização deste dispositivo na dermorrafia da genitália de equinos, Rabelo et al. (2012) fizeram referência a utilização do cápton em procedimentos cirúrgicos envolvendo a genitália externa de touros. Para os autores este dispositivo contribuiu de forma decisiva para que a reparação tecidual ocorresse sem intercorrências como deiscência e infecções, portanto está de acordo com a conduta executada nessa descrição.

\section{Referências}

BADIAL, P.R.; OLIVEIRA FILHO, J.P.; CUNHA, P.H.J.; CAGNINI, D.Q.; DELFIOL, D.J.Z. Carcinoma de células escamosas associado à ferida crônica de um equino com astenia cutânea. In: CONFERÊNCIA ANUAL DA ABRAVEQ, 11., 2010, São Paulo. Disponível em: http://www.abraveq.com.br/artigos_2010_ cartazes/63.pdf. Acesso em: 25 de setembro de 2013.

BOGAERT, L.; WILLEMSEN, A.; VANDERSTRAETEN, E.; BRACHO, M.A.; DE BAERE,C.; BRAVO, I.G.; MARTENS, A. EcPV2 DNA in equine genital squamous cell carcinomas and normal genital mucosa. Veterinary Microbiology, v. 158, p. 3341, 2012.

CATTELAN, J.W.; BARNABÉ, P.A.; TONIOLLO, G.H.; CADIOLI, F.A. Criptorquidismo em equinos. Revista CFMV, n. 32, p. 4551, 2004

COELHO, C.M.M.; SILVA, O.C.; SILVA, L.A. F.; RABELO, R.E.; ORLANDO, C.F.P.; ARAÚJO, I.L.F. Enfermidades cirúrgicas do aparelho reprodutor masculino equino: aspectos clínicos e terapêuticos. Revista do Conselho Federal de Medicina Veterinária, v.18, n. 55, p. 58-66, 2012.

EDWARDS, J.F. Pathologic conditions of the stallion reproductive tract. Animal Reproductive Science, v.107, n. 3, p.197-207, 2008.

EURIDES, D.; SILVA, L.A.F. Métodos de preparo de rufiões bovinos e equinos. Goiânia: Talento, 2002, 112 p.
Ainda, em relação à circuncisão craniocaudal com encurtamento do pênis, nesse estudo não foi necessária a realização das incisões longitudinais para promover a coaptação das bordas. Tal fato deveu-se a compatibilidade entre os diâmetros das bordas do tecido fibroso do pênis e da parte interna do prepúcio. Outros autores citaram que a incompatibilidade entre os diâmetros é comum ao empregar essa técnica no preparo de rufiões equinos, sendo a manobra necessária (Silva et al., 1991, Eurides e Silva, 2002). Acredita-se que no referido caso, por remover somente o segmento afetado pela lesão, não houve necessidade de se efetuar uma circuncisão muito cranial na parte interna do prepúcio, o que evitou a diferença entre os diâmetros.

Vale ressaltar que a adoção da solução de Dakin por ocasião da antissepsia da ferida cirúrgica, mostrou-se eficiente quanto à redução bacteriana, além de ser uma alternativa viável a baixo custo. Tal produto pode ser considerado uma opção em substituição ao clorexidine $4 \%$ e a tintura de iodo $2 \%$, desde que seja utilizado após a remoção dos pontos de algodão ou quando se opta por pontos de poliamida, como nos casos relatados, concordando, dessa forma, com as recomendações de Silva et al. (2000).

\section{Conclusão}

Os exames clínicos, histopatológicos e citopatológicos apresentaram-se fundamentais para se estabelecer o diagnóstico e prognóstico do carcinoma de células escamosas acometendo a genitália externa de equinos machos. $O$ tratamento cirúrgico, em ambos os casos, empregando como alternativa a sutura captonada mostrou-se eficiente evitando complicações comumente observadas nestas intervenções. A solução de Dakin demonstrou também ser uma alternativa eficaz e de baixo custo podendo ser empregada também no pós-operatório imediato.

GINN P.E.; MANSELL J.E.K.L.; RAKICH P.M. Skin and appendages. In: Jubb, Kennedy and Palmer's Pathology of Domestic Animals. 5. ed. Philadelphia: Elsevier, 2007. v. 1. p. 553-781.

MASSONE, F. Anestesiologia Veterinária: farmacologia e técnicas. 4. ed. Rio de Janeiro: Guanabara Koogan, 2003, 326 p.

MCGAVIN, M.D.; ZACHARY, J.F. Bases da Patologia em Veterinária. 4. ed. Rio de Janeiro: Elsevier, 2009, 1476 p.

MEUTEN D.J. Tumors in Domestic Animals. 4. ed. Ames: lowa State Press, 2002, $788 \mathrm{p}$.

MICALI, G.; NASCA, M.R.; INNOCENZI, D.; SCHWARTZ, R.A. Penile cancer. Journal of the American Academy of Dermatology, v. 54, p. 369-391, 2006.

RABELO, R.E.; VULCANI, V.A.S.; SANT'ANA, F.J.F.; VICENTIN, F.R.; HELRIGEL, P.A.; BATISTA, J.F. Complicações póscirúrgicas após a excisão de carcinoma de células escamosas na região perianal em fêmea equina. Veterinária e Zootecnia, v. 20, n.1, p. $47-51,2013$.

RABELO, R.E.; RABELO, T.H.P.; RIBEIRO, G.O.; VULCANI, V.A.S.; HELRIGEL, P.A. Necrose da extremidade livre do pênis como complicação da enfermidade acropostite-fimose em touros. In: CONGRESSO BRASILEIRO DE CIRURGIA E ANESTESIOLOGIA VETERINÁRIA, 10., 2012, Florianópolis, Anais... Florianópolis: Escala, 2012. p. 45-47. 
REED, S.M.; BAYLY, W.M. Medicina Interna Equina. Rio de Janeiro: Guanabara Koogan, 2000. 938 p.

SCOTT, D.W.; MILLER, W.H.J. Equine Dermatology. 2. ed. Missouri: Elsevier Science, 2010, 552 p.

SILVA, D.A.R.; COSTA, M.M.; VARGAS, A.C.; ALIEVI, M.M.; SCHOSSLER, J.E.W. O gluconato de clorexidina ou o álcooliodo-álcool na antissepsia de campos operatórios em cães. Ciência Rural, v. 30, n. 3, p. 431-437, 2000.

SILVA, L.A.F.; RABELO, R.E.; GODOY, R.F.; SILVA, O.C.; FRANCO, L.G.; COELHO, C.M.M.; CARDOSO, L.L. Estudo retrospectivo de fimose traumática em equinos e tratamento utilizando a técnica de circuncisão com encurtamento de pênis (1982-2007). Ciência Rural, v. 40, n. 1, p. 1-7, 2010.

SILVA, L.A.F..; CARNEIRO, M.I.; FIORAVANTI, M.C.S.; MIRANDA, A.F.; BERNIS, W. O. Técnica de circuncisão com encurtamento do pênis para obtenção de rufiões equinos. Arquivo Brasileiro de Medicina Veterinária e Zootecnia, v. 47, n. 6, p.789-798, 1995.

SILVA, L.A.F.; ALVES, G.E.S.; CARNEIRO, M.I.; SILVA, O.C. Avaliação do desempenho de rufiões equinos preparados através da amputação parcial do pênis. Arquivo EMV - UFBA, v. 14, n. 1, p. 63-78, 1991.
THOMASSIAN, A. Afecções do aparelho reprodutor do macho. In: Enfermidades dos Cavalos. 4. ed. São Paulo: Varela. 2005, p. 244-248.

VALENTINE, B.A. Equine cutaneous non-neolastic nodular and proliferative lesions in the Pacific Northwest. Veterinary Dermatology, n. 16, p. 425-428, 2005.

VAN DEN TOP, J.G.B.; ENSINK, J.M.; BARNEVELD, A.; VAN WEEREN, P.R. Penile and preputial squamous cell carcinoma in the horse and proposal of classification system. Equine Veterinary Education, v. 23, n. 12, p. 636-648, 2011.

VAN DEN TOP, J.G.B.; ENSINK, J.M.; GRÖNE, A.; KLEIN, W.R..; BARNEVELD, A.; VAN WEEREN, P.R. Penile and preputial tumors in the horse: Literature review and proposal of a standardised approach. Equine Veterinary Journal, v. 42, n. 8, p. 746-757, 2010.

VAN DEN TOP, J.G.B.; DE HEER, N.; KLEIN, W.R.; ENSINK, J.M. Penile and preputial tumours in the horse: A retrospective study of 114 affected horses. Equine Veterinary Journal, v. 40, p. 528-532, 2008. 